\title{
Seasonality Effect: What Risk Switch Strategy is Profitable for U.S. Stocks?
}

\author{
Ulrich R. Deinwallner, $\mathrm{PhD}^{*}$
}

PhD Management and Finance, Walden University, USA

DOI: $10.36348 /$ sjef.2020.v04i03.003 $\quad$ | Received: 29.02.2020 | Accepted: 07.03.2020 | Published: 10.03 .2020

*Corresponding author: Dr. Ulrich R. Deinwallner

\section{Abstract}

The general problem of this study was that certain stock market sectors can benefit more than other sectors from seasonality's (Halloween indicator). It was unclear how seasonality of stock markets impact risk stock strategies while controlling for stock market sectors, when constructing U.S. security portfolios. The purpose of this quantitative, comparative study was to test the influence of a summer and winter effect on the profitability of risk stocks strategies for Standard and Poor's (S\&P) 500 stock portfolios. The research question was: How does seasonality impact the profitability of risk stock strategies while controlling for stock market sectors for U.S. security portfolios? For the analysis a comparison was conducted, while computing the Betas (B), Idiosyncratic Volatility (IV), Capital Asset Price Models (CAPM), annualized returns, and Sharpe ratios for an analysis. A key result of the study was that during the winter months high $\mathrm{B}$ and medium ${ }_{\mathrm{B} \& \mathrm{IV}}$ until high $\mathrm{B \& IV}_{\mathrm{V}}$ stock selections were the most profitable risk stock strategies and for the summer months low IV, B, IV\&B stock selections were most profitable risk stock strategies to trade. The sector selection and the stock selection brought higher returns as reported by other studies, of for example $\left(r_{\text {Strategyl }}=108.40 \%\right.$ annualized return) in this study. Seasonality's were present in the U.S. stock markets and the investor could capitalize on this effect through a risk stock strategy switch, which is further described in this study and can improve the previous form of investing (i.e., of buying all stocks during winter and changing to Treasury Bill during summer).

Keywords: Beta; idiosyncratic volatility; investment strategy; portfolio management; risk stock strategies; sectors; seasonality.

Copyright @ 2020: This is an open-access article distributed under the terms of the Creative Commons Attribution license which permits unrestricted use, distribution, and reproduction in any medium for non-commercial use (NonCommercial, or CC-BY-NC) provided the original author and source are credited.

\section{INTRODUCTION \\ Risk stock strategies}

Several researchers discussed the issue of risk and the influence on stocks. In regard of levered investments, Asness, Frazzini, and Pedersen [1] found that investors do not prefer leverage for their investments. Investors rather invest in high risk stocks, than to expose their investment to leveraged risks [1]. Baker, Bradley, and Wurgler [2] focused in their research on low-risk stock strategies. Baker et al. reported that low-risk stocks are often underweighted in portfolios, because other investments can better replicate the movement of a benchmark, such as the Standard and Poor's (S\&P) 500 for example as a Benchmark. Baker et al. tested their assumptions with the return data of mutual fund in a study. In contrary, Chow, Hsu, Kuo, and Li [3] had an focus in their research on low-risk stocks and saw that low volatility investing offers investors higher returns, while the risk remains low compared to stock weighted index investing. A lower volatility of stocks has the effect that the market factor exposure is reduced and the high returns are connected to a better risk and return relation [3]. Fong and Koh [4] confirmed that low-beta stocks performed better than high-beta stocks, when riskadjusted returns were compared. Fong and Koh recommend low-risk portfolios as alternative to stock/bond portfolio allocation strategies for long-term oriented investments. Walkshäusl [5] explained that a relationship between low volatility of international equities and high quality of the investigated worldwide firms could exits. Walkshäusl agreed to Fong and Koh's findings that low-risk stocks are a good choice for longterm investments because of the high quality that these firms exhibit. Essentially, low-risk stocks can generate higher returns for investors and can be an alternative to stock/bond portfolio allocation strategies.

\section{Seasonality of stocks}

Another relevant issue to mention for risk stock strategies is the impact of seasonality. Bouman and Jacobsen [6] reported that a buy and hold $(\mathrm{BH})$ 
strategy of an investment in for example an index security can be outperformed by a strategy of buying in the nonsummer months stocks and by buying in the summer months bonds or treasury bills in order to outperform a simple BH strategy of an index security. In regard of the reason of stock seasonality, Bouman and Jacobsen saw a cause of stocks and risk aversion of investors caused by the vacations that occur during the summer months. Hong and $\mathrm{Yu}$ [7] supported this assumption of Bouman and Jacobsen with evidence of vacation-behavior in stock markets during the summer months, which impacted the tested security returns. Kamstra, Kramer and Levi [8] argued that the risk aversion of investors for stock investments in summer months was caused by a seasonal affected disorder. Cao and Wei [9] assumed a connection between a seasonal effect and a change in the investor's behavior of stock investing caused by a temperature change. All of these researchers argued for a behavioral explanation, when trying to explain the cause of this market-wide phenomenon of seasonality impacting stock returns.

Other causal assumptions for seasonality effects for stocks came by researchers in the subsequently considered studies. Jacobsen and Marquering [10] presented findings to several correlated causes of seasonality, while Jacobsen and Marquering [10] reported that seasonally for stocks might be cause by production and consumption, natural causes like the weather, other causes could be Christmas sales, economic actions, school year and travel months, or the automobile production could all impact the seasonality of stocks. From these assumptions, Jacobsen and Marquering [11] hypothesized that seasonality effects for stocks might vary across sectors. Therefore, several factors could be causal of seasonality effects of stocks and the variation of seasonality effects across sectors should have a close focus when investigating the effects.

Sectors and industries needed to be further investigated for the seasonality effects of stocks. Jacobsen and Visaltanachoti [11] conducted this research of seasonality for different sector stock returns for the U.S. general market, and found in their study that the production sector and consumer sector seemed most profitable compared to other sectors. In specific, the consumer sector outperformed a $\mathrm{BH}$ strategy during the summer months, while the production section outperforms a $\mathrm{BH}$ strategy during the nonsummer months. Fiore and Saha [12] presented findings that high Beta (B) and high Idiosyncratic Volatility (IV) stocks responded to seasonality significantly, while low $\mathrm{B}$ and IV stocks exhibited a lower response. In specific, in summer the low B stocks and low IV stocks outperformed high B stocks and high IV stocks. Stocks that exhibited both character (i.e., low B \& low IV) outperformed stocks with only one of the risk attributes (i.e., low B or low IV) in Fiore and Saha's research. Fiore and Saha corroborated and confirmed Jacobsen and Visaltanachoti's findings that high B stocks outperform during the nonsummer months investments that followed a low risk stock strategy. However, the nonsummer month's returns were greater, than the summer month's returns in comparison of the seasonality returns that were connected to the risk stock strategies. Fiore and Saha stressed that an inversion of the risk and return relationship that was discussed in several prior studies, might be impacted by a seasonality of the investigated stock returns. Essentially, Jacobsen and Visaltanachoti and Fiore and Saha provided specific asset strategy recommendations of an investment during the summer months or during the nonsummer months.

\section{CAPM}

The capital asset price model (CAPM) has its relevance for several studies that investigate stock returns because of the risk measures $\mathrm{B}$ and idiosyncratic risk. Sharpe [13] and Lintner [14] first proclaimed that the equity exposure to a market movement can be seen as a relevant risk measure. This means that the risk of equity can be measured by the degree of impact for the volatility of a well diversified market portfolio. The risk measure of Sharpe and Lintner was referred to as B and represented equity's covariance with the market. For example, a high CAPM B value means that an investor can be rewarded with a high stock return, in connection to the occurrence of a positive market movement, because the investor has to bear a higher risk. According to the modern portfolio theory and the CAPM theory, the CAPM predictions of the expected return can diversify away the idiosyncratic risk for an asset $[12,15]$. A risk premium is not paid for idiosyncratic risk, which instead has a similar expected return as a risk-free security [12]. Therefore, the CAPM is relevant as a model to closer inspect two risk measures for a stock: (a) the B and (b) the idiosyncratic risk.

Next to others, four scholarly articles are relevant in regard of idiosyncratic risk determined by asst price valuation models. Ang, Hodrick, Xing and Zhang [16, 17] found, through the application of the Fama French three factor model (FF3FM), that stocks through out several countries with a low IV, can outperform stocks with a high IV in comparison. Malkiel and Xu [18] and Ewens, Jonesn and RhodesKropf [19] reported that IV should be priced for stocks, in case those investors are not fully able to diversify the idiosyncratic risk in their investment portfolios. Research contributions to these assumptions came from Fiore and Saha [12] who investigated the performance of a low and a high B and a low and a high IV stock selection in their study. Therefore, B and especially idiosyncratic risk do exhibit some relevance for investment strategies, other than expected according to the IV and the diversification assumptions of researchers. 
Finally, it is to mention that several researchers have criticized the CAPM in their studies. Black [20], Black, Jensen, and Scholes [21], and Haugen and Heins [22] reported deficits for the CAPM B and for predicting returns that the market factor does not capture entirely how an asset is priced. Fama and French [23] added that the size of an asset had also an impact on the B value and on the CAPM predictions of the asset price. Essentially, the CAPM is a simpler asset price valuation model that is commonly used to predict the expected return. However, the CAPM is criticized in the scholarly literature for a certain mispricing potential because of the CAPM's simplicity (i.e., for not considering size factors and other influencing factors in the asset valuation).

The current situation is that higher returns of low-risk stock strategies and seasonality effects have been investigated by Fiore and Saha [12]. In the research of Fiore and Saha study, a winter and summer effect was differentiated for low and high risk stock strategies. Bouman and Jacobsen [6] and Jacobsen and Visaltanachoti [11] also investigated a seasonality effect for U.S. stocks, while Jacobsen and Visaltanachoti referred to seasonality's as the Halloween indicator. Essentially, several researchers presented findings to seasonality for stock market returns and Fiore and Saha connected the issue to risk stock strategies.

The general problem is that Jacobsen and Visaltanachoti [11] reported in their study that, in connection to the Halloween indicator, certain stock market sectors and industries benefit more than other sectors from seasonality's, for example the equally weighted (EW) production stock sector with returns of ( $r_{\text {production sector_winter }}=1.34 \%$ per month) where $r$ is the return, and EW consumer stock sectors with returns of $\left(r_{\text {consumer sector_summer }}=0.82 \%\right.$ per month) during 1926 2006. This means that the investigation of the presented data occurred nearly 13 years ago.

The specific problem is to understand the impact of seasonality on risk stock strategies while controlling for stock market sectors, when constructing U.S. security portfolios. Through the findings of Fiore and Saha [12], investors could understand what strategies might be beneficial for all U.S. stocks in general. However, investors who practically want to apply risk stock strategies according to sectors and industries for their investment decisions can find through my study a more differentiated approach for the S\&P 500 U.S. stock market data and the construction of portfolios.

The purpose of this quantitative, comparative study is to test the influence of a summer and winter effect on the profitability of risk stock strategies, while controlling for sectors of S\&P 500 stock portfolios. Therefore, this study is guided by one research question (R1): How does seasonality impact the profitability of risk stock strategies while controlling for stock market sectors for U.S. security portfolios?

\section{Six hypotheses are relevant to answer the research question}

$H_{0} 1$ : if the seasonality is assessed for the S\&P500 index returns, then the returns do not differ significantly according to the seasonality

$H_{1} 1$ : if the seasonality is assessed for the S\&P500 index returns, then the returns differ significantly according to the seasonality

$H_{0} 2$ : if seasonality of the S\&P 500 is compared while controlling for the sectors of the S\&P 500, then the consumer and production sector of the S\&P500 will not show significantly higher return results compared to the other sectors.

$H_{1} 2$ : if seasonality of the S\&P 500 is compared while controlling for the sectors of the S\&P 500, then the consumer and production sector of the S\&P500 will show significantly higher return results compared to the other sectors.

$H_{0} 3$ : if the average monthly returns are compared for the two S\&P500 most seasonality dominant sectors and controlled for B and the IV while differentiating the results by five quintiles, then the sector average monthly returns are not the largest for the lowest quintile when sorting the results by B and IV.

$H_{1} 3$ : if the average monthly returns are compared for the two S\&P500 most seasonality dominant sectors and controlled for B and the IV while differentiating the results by five quintiles, then the sector average monthly returns are the largest for the lowest quintile when sorting the results by B and IV.

$H_{0} 4:$ if 10,15 , and max stock portfolios are constructed from the two most seasonality dominant S\&P500 sectors while controlling for seasonality and selecting the stocks according to the lowest, medium, and highest quintile $\mathrm{B}$ and IV values, then 10 stock portfolios, for the winter months, with high ${ }_{B}$ and high selected return results are not greater than the other medium or high ${ }_{B}$ or high ${ }_{\text {IV }}$ selected return values.

$H_{1} 4$ : if 10,15 , and max stock portfolios are constructed from the two most seasonality dominant S\&P500 sectors while controlling for seasonality and selecting the stocks according to the lowest, medium, and highest quintile $\mathrm{B}$ and IV values, then 10 stock portfolios, for the winter months, with high ${ }_{B}$ and high selected return results are greater than the other medium or high or high $_{\mathrm{IV}}$ selected return values. 
$H_{0}$ 5: if low, medium and high quintile $\mathrm{B}$ and IV combinations for the two most dominant sector portfolios of the S\&P500 stocks are compared while controlling for seasonality, then the high B\&IV $_{\text {. }}$ combination for a 10 stock portfolio in winter months is not significantly more profitable, than the other $\operatorname{low}_{\mathrm{B} \& \mathrm{IV}}$ or medium B\&IV $_{\text {combinations. }}$

$H_{1}$ 5: if low, medium and high quintile $\mathrm{B}$ and IV combinations for the two most dominant sector portfolios of the S\&P500 stocks are compared while controlling for seasonality, then the high B\&IV combination for a 10 stock portfolio in winter month is significantly more profitable, than the other $l_{\text {ow }}$ \&IV or medium $_{\text {B\&IV }}$ combinations.

$H_{0}$ 6: if the low, medium, and high $\mathrm{B}, \mathrm{IV}$, and B\&IV risk stock strategies of the two most dominant sector portfolios of the S\&P500 stocks, BH strategy (market index), and Treasury Bills (T-Bills) strategy with a winter and a summer switch are annually compared, then the high ${ }_{B}$ risk stock strategy for winter and a low $\mathrm{w}_{\mathrm{B} \& \mathrm{IV}}$ risk stock strategy for summer are not significantly more profitable compared to the other risk stock switch strategies.

$H_{l}$ 6: if the low, medium, and high B, IV, and $\mathrm{B} \& \mathrm{IV}$ risk stock strategies of the two most dominant sector portfolios of the S\&P500 stocks, BH strategy (market index), and T-Bills strategy with a winter and a summer switch are annually compared, then the high risk stock strategy for winter and a low B \&IV $_{\text {risk stock }}$ strategy for summer are significantly more profitable compared to the other risk stock switch strategies.

In this study, I consider stock market data from the S\&P 500 and the data provide by Kenneth French, to conduct several comparisons and to compute a CAPM to obtain the B and the IV values during the time period of January 01, 1999 until December 31, 2018. I test six hypotheses to answer the research question. First, I test for seasonality's and I compare the winter and the summer month returns of the S\&P500 index and for the T-Bills. Second, I test the S\&P 500 stock data according to the S\&P 500 sectors for seasonality's of a winter and a summer effect. Third, I select the Industrials and the Materials sectors as most robust during crises obtained through a sub-period comparison. I computed the B and the IV coefficients for both selected sectors (Industrials and Materials) and their returns and for one until five quintiles for the results. Forth, I combine the quintiles in three dimensions: low, medium, and high for the B and IV sector stock values. I then assign the return data in the best case to the portfolio sizes 10, 15 and max amount of stocks, while also controlling for seasonality again. Fifth, I conduct the same analysis as in Hypothesis 4; however, I test for low $_{\text {B\&IV }}$ and high $h_{\text {B\&IV }}$ combinations and their profitability in form of monthly returns. Sixth, I conduct a strategy switch comparison, where depending on the winter months or the summer months the risk stock strategies are being switched. I can corroborate Fiore and Saha [12] findings that a seasonality switch during the winter months with high and medium B\&IV $_{\text {until high }}$ B\&IV stock selections are most profitable and for summer months $\operatorname{low}_{\mathrm{IV}}$, low $\mathrm{l}_{\mathrm{B}}$, and low $_{\text {B\&IV }}$ stock selections are most profitable, with annual strategy returns of for example $\left(r_{\text {Strategy } 1}=\right.$ $108.40 \%$ ) from Table 6 . The study's findings can contribute to the scholarly literature of stock market seasonality and risk stock strategies in a more differentiated form, since a stock selection and a construction of portfolios was conducted. Especially the stock selection from individual stock market sectors and the formation of portfolios brought a large difference in the annual returns compared to Fiore and Saha reported findings. I conclude at the end of the paper that seasonality can be found in the U.S. stock markets and risk stock switch strategies are most profitable for investors to consider. The findings of the paper can bring positive social change, since private investors can compare their own strategy results through a switch strategy comparison in this paper for their investment decisions. Therefore, this paper can be interesting for private investors, institutional investors, and portfolio managers et cetera.

\section{DATA AND METHODOLOGY}

For the analysis, I use dividend adjusted daily closing prices from the S\&P 500 over the time period of January 01, 1999 until December 31, 2018 (20 years). I also use the risk factor data that is provided by Kenneth French's website to compute the CAPM, published on the website https://mba.tuck.dartmouth.edu/pages/faculty/ken.frenc h/data_library.html [24]. I obtained the S\&P 500 data from the source Yahoo!Finance [25].

I limit the results in this study of U.S. security portfolios to the data of the S\&P 500 and the data of Kenneth French (i.e., T-Bills). The S\&P 500 is a U.S. stock market index that is composed and categorized through different sectors and different industries. A sector can be seen as a broad grouping of firms that have comparable economic characteristics; where subcategories of these sectors are referred to as the industries. For the study, I will test seasonality effects that might occur in 11 sectors of the S\&P500 data; while the S\&P 500 stocks are sorted and analyzed according to each sector. It is to mention that no larger findings were reported between the investigated sectors in Bouman and Jacobsen's [6] study results, because the sectors and the years were limited in the study. Jacobsen and Visaltanachoti [11] used a much longer time-period of more than 80 years and a larger number of sectors and partitioning to find a seasonality effect for the investigated sectors and industries. My assumptions are that the S\&P500 is sufficiently diversified according to sectors and industries. And, that the consideration of 20 years of data might cause a 
problem to observe seasonality effects, but the amount of data is current and practicable for common investors to replicate. Further, I will test the impact of risk on S\&P500 stocks, by considering the CAPM B and IV. I will compare different risk stock switch strategies to answer the research question and to determine the most profitable strategies for an investment.

The CAPM can help to compute the systematic risk and the unsystematic risk in this study [26]. Through the computation of the CAPM, the risk stock strategies can be further investigated in the subsequent analysis. The equation for the CAPM is [12]:

$r_{i}=R_{F}+\beta_{i}\left(R_{m}-R_{F}\right)+\varepsilon_{i}$

Where,

$\left(R_{M}-R_{F}\right)=$ excess market return

$R_{F}=$ risk free rate $\left(R_{F}\right)$

$r_{i}=$ excess return of portfolio and $i=1, \ldots, k$

$\beta_{i}=\mathrm{B}$ or the sensitivity of the security $i=1, \ldots, k ; k=$ the number of variables

$\varepsilon_{i}=$ error-term

While,

$I V_{i}=\sqrt{\operatorname{var}}\left(\hat{\varepsilon}_{i}\right)$ or the standard deviation of the errorterm.

Through the Sharpe ratio, the investor can assesses the average excess return value per unit of the underlying systematic risk. The Sharpe ratio allows an evaluation of assets or a portfolio's performance associated to the underlying risk. The larger the Sharpe ratio value is, the more attractive an investment is because of the risk and return relation.

$$
S R_{i}=\frac{\left(r_{i}-R_{f}\right)}{\sigma_{i}}
$$

Where, $r=$ stock or portfolio return, $R_{f}=$ the risk free rate, $\sigma=$ standard deviation, of the stock or portfolio $i=1, \ldots, k ; k=$ the number of variables; $S R$ $=$ Sharpe Ration. In this paper, I compute the SR without the risk free rate adjustment (subtraction) and simply divide the portfolio return through the average standard deviation.

For the research design, I will conduct the following quantitative comparatives, tests, and analyses. First, I will generate an overview of the data distribution for the T-Bills and the S\&P500 index average returns transformed from continuous returns into discrete returns, while controlling the data for summer and winter months. The time periods for the seasonality of summer months are (May-October) and of winter months are (November-April) [11]. The tested hypotheses $(\mathrm{H})$ are $H_{1} 1$ : If the seasonality is assessed for the S\&P500 index returns, then the returns differ significantly according to the seasonality.

Second, I will test and compare the seasonality for the sectors while displaying the industries of the S\&P500 stocks through a comparative table. Jacobsen and Visaltanachoti [11] found significant results for the consumer and production sector in their research. I can hypothesize that these results can relate to the consumer and to the industry sector for the S\&P500 sectors. $H_{1} 2$ : if seasonality of the S\&P 500 is compared while controlling for the sectors of the S\&P 500, then the consumer and production sector of the S\&P500 will show significantly higher return results compared to the other sectors.

Third, I will provide a return overview to the two most profitable seasonality sectors of the S\&P500, while controlling for the $\mathrm{B}$ and the IV. The mean returns are sorted by B and sorted by IV according to five quintiles for the most seasonality dominant sector stocks of the S\&P500. Fiore and Saha [12] reported high return results for $\operatorname{low}_{\mathrm{B}}$ and $\operatorname{low}_{\mathrm{IV}}$ values in their total return comparison of all quintiles. $H_{1} 3$ : If the average monthly returns are compared for the two S\&P500 most seasonality dominant sectors and controlled for B and the IV while differentiating the results by five quintiles, then the sector average monthly returns are the largest for the lowest quintile when sorting the results by $\mathrm{B}$ and IV.

Fourth, I will construct stock portfolios from the two most profitable seasonality S\&P500 sectors. For the portfolios, I will control for high, medium, low B and IV and for a winter and summer effect. Fiore and Saha [12] reported greater returns for the winter months compared to the summer months. The portfolios will have the size 10,15, max stocks for three dimensions of investment amounts, where max stocks are all of the remaining stocks in the selected portfolio. $H_{1} 4$ : if 10 , 15 , and max stock portfolios are constructed from the two most seasonality dominant S\&P500 sectors while controlling for seasonality and selecting the stocks according to the lowest, medium, and highest quintile B and IV values, then 10 stock portfolios, for the winter months, with high ${ }_{B}$ and high ${ }_{I V}$ selected return results are greater than the other medium or high ${ }_{B}$ or high selected return values.

Fifth, I will compare the results for combinations of risk while controlling for seasonality of the two most profitable S\&P500 sectors. Fiore and Saha [12] reported that $\operatorname{low}_{B}$ and $\operatorname{low}_{\mathrm{IV}}$ values exhibited greater returns for the summer months compared to the summer months of high ${ }_{\mathrm{B}}$ and high $\mathrm{IV}_{\mathrm{IV}}$ values. $H_{1}$ 5: if low, medium and high quintile $\mathrm{B}$ and IV combinations for the two most dominant sector portfolios of the S\&P500 stocks are compared while controlling for seasonality, then the high $h_{B}$ IV combination for a 10 stock portfolio 
in winter month is significantly more profitable, than the other low B\&IV $_{\text {or medium }}$ \&IV combinations.

Sixth, I will test different annual strategies that combine winter and summer strategy switches for the most profitable seasonality sector portfolios of S\&P500 stocks. Fiore and Saha [12] reported for the most profitable risk stock strategy, which considered a summer and winter switch combination, a high

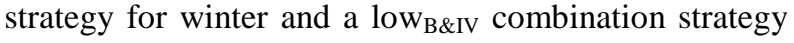
in summer with ( $r_{\text {winter_highB_and_summer_lowB \&IV }}=16.74 \%$ annual return; Sharpe ratio $=0.5955) . H_{1} 6$ : if the low, medium, and high B, IV, and B\&IV risk stock strategies of the two most dominant sector portfolios of the S\&P500 stocks, BH strategy (market index), and TBills strategy with a winter and a summer switch are annually compared, then the high ${ }_{B}$ risk stock strategy for winter and a low $\mathrm{B}_{\mathrm{B} \& \mathrm{IV}}$ risk stock strategy for summer are significantly more profitable compared to the other risk stock switch strategies.

Because private investors tend to lose capital in the financial markets, this study is for educational reasons, does not represent investment advice, and investors should conduct their own research before investing their capital [27]. The threads to external validity are that the analyzed sectors might not be the most profitable sectors for future stock market developments. In regard of the internal validity, the SR values might be too high because the returns were not adjusted by the risk free rate, also the standard deviations of the portfolios are slightly too high because correlation effects were not considered as explained in the method section earlier. This can have an effect in comparing the SR values of this paper with other SR values of other research papers. Further, the risk stock switch strategy returns were annualized. This means that larger deviations could occur for the stocks during a year and for the actual annual return results.

\section{EMPIRICAL FINDINGS \\ Analysis and Discussion of H1}

For the analysis of $H 1$, I compared the winter and the summer month returns of the S\&P500 index and for the T-Bills. From the analysis of the S\&P 500 index returns, I can find in Table 1 for the selected time period 1999-2018 that a summer and winter effect was present. During the winter months the average monthly return was $\left(r_{w}=0.64 \%\right)$ and during the summer months the average monthly return was $\left(r_{s}=-0.03 \%\right)$. I could reject the Null Hypothesis 1 at a $1 \%$ alpha level according to the results of a $t$-test with $t(2468)=424, p$ $<.001$, where the average monthly confidence interval $(C I)$ of the S\&P500 returns was $C I_{99 \%}[0.15 \%, 0.44 \%]$.

Table-1: Seasonality test for S\&P 500 and T-Bills from 1999-2018

\begin{tabular}{|l|c|c|c|}
\hline & Average monthly return (\%) & Difference \\
\hline S\&P 500 & Winter & Summer & 0.66 \\
\hline T-Bills & 0.63 & -0.03 & 0.00 \\
\hline Excess return & 0.16 & 0.15 & -0.18 \\
\hline $\begin{array}{l}\text { Note. All values are monthly average returns in (\%). The T-Bills values are obtained from Kenneth French data } \\
\text { webpage. In the Table, a differentiation was conducted between winter and summer months. }\end{array}$ \\
\hline
\end{tabular}

\section{Analysis and Discussion of $\mathrm{H2}$}

For the analysis of $H 2$, I differentiated the S\&P 500 stock data according to the S\&P 500 sectors and controlled for a winter (W) and a summer (S) effect. The three highest average monthly returns during the winter months could be observed from Table 2 for the Energy sector $\left(r_{\text {Energy_ } W}=4.53 \%\right.$ per month), Industrials sector ( $r_{\text {Industrials }{ }_{-} W}=3.53 \%$ per month), and Materials sector $\left(r_{\text {Materials }-W}=3.81 \%\right.$ per month). For a subsequent strategy comparison, where a strategy is twice a year switched, it is relevant to select the largest winter returns through an analysis, since the winter months perform better compared to summer months. For a strategy switch, the differences among winter and summer months should be significantly large for high return results of combined strategies. I provide in the Appendix a sub-period comparison for a robustness test (Table A1 and Table A2). Interestingly, the Industrials and Materials sectors seem robust as the most profitable sectors for a winter effect during the years 1999-2008 and 2009-2018. The Energy sector performed weaker during winter in the sub-period years 1999-2008 ( $r_{\text {Energy } W}=0.25 \%$ per month) compared to the other sector return results. In consequence, I could not corroborate the findings of Jacobsen and Visaltanachoti [11] for the profitability of the production or the consumer sector directly. However, the Industrials and Materials sector are related to a Production section as described in Jacobsen and Visaltanachoti's study, and according to Table A 2 the Consumer Discretionary (CD) sector was most profitable with $\left(r_{C D_{-} W}=4.93 \%\right.$ per month) during the sub-period 2009-2018. Essentially, I could not reject the Null Hypothesis 2 at a $1 \%$ alpha level because the Consumer sector did not exhibit the highest return results in comparison to the other sectors during the tested time period 1999-2018. 
Table-2: S\&P 500 sectors from 1999-2018

\begin{tabular}{|l|c|c|c|}
\hline \multirow{2}{*}{ Communication Service } & \multicolumn{3}{|c|}{ Average monthly return (\%) } \\
\cline { 2 - 4 } & Winter & Summer & Mean \\
\cline { 2 - 4 } & 1.27 & 0.43 & 0.85 \\
\hline Consumer Discretionary & 3.01 & 0.06 & 1.54 \\
\hline Consumer Staples & 1.14 & 0.80 & 0.97 \\
\hline Energy & $\mathbf{4 . 5 3}$ & $\mathbf{- 0 . 0 9}$ & $\mathbf{2 . 2 2}$ \\
\hline Financials & 1.29 & 0.20 & 0.75 \\
\hline Health Care & 2.49 & 0.88 & 1.68 \\
\hline Industrials & $\mathbf{3 . 5 3}$ & $\mathbf{0 . 0 8}$ & $\mathbf{1 . 8 1}$ \\
\hline Information Technology & 2.13 & 0.52 & 1.32 \\
\hline Materials & $\mathbf{3 . 8 1}$ & $\mathbf{- 0 . 1 4}$ & $\mathbf{1 . 8 3}$ \\
\hline Real Estate & 2.71 & 0.52 & 1.61 \\
\hline Utilities & 1.56 & 0.57 & 1.06 \\
\hline $\begin{array}{l}\text { Note. All values are monthly average returns in (\%). The results were computed } \\
\text { for each of the 11 sectors of the S\&P 500 stocks. In the table, a differentiation } \\
\text { occurred between winter and summer results of the sector return data. The } \\
\text { arithmetic mean displays the average monthly return for each sector in } \\
\text { combination of the winter and the summer month returns. }\end{array}$ \\
\hline
\end{tabular}

\section{Analysis and Discussion of $\mathrm{H3}$}

The Industrials and the Materials sectors were considered for the analysis of $H 3$, since both sectors were robust in a sub-period comparison. I computed the $\mathrm{B}$ and the IV coefficients for both selected sectors and their returns. Then, I ranked the returns according to the $\mathrm{B}$ and the IV values and sorted the returns with their average value in a one until five quintiles Table.
From Table 3, I could find that the lowest quintiles did not exhibit the highest return results; however, the values of the 2 quintile seemed to outperform the other values in comparison. This means for my further analysis that I will select the two lowest and the two highest quintiles when following a B and an IV selection strategy (in other words, I will sort the quintiles subsequently in only three dimensions, not in five).

Table-3: Average monthly returns (\%), 1999-2018

\begin{tabular}{|c|c|c|}
\hline \multicolumn{3}{|c|}{ Industrials } \\
\hline Quintile & Sorted by B & Sorted by IV \\
\hline Low & 0.36 & 0.79 \\
\hline 2 & 0.93 & 0.93 \\
\hline 3 & 0.96 & 0.42 \\
\hline 4 & 0.59 & 0.26 \\
\hline High & 0.50 & 0.31 \\
\hline All & 3.34 & 2.71 \\
\hline \multicolumn{3}{|l|}{ Materials } \\
\hline Quintile & Sorted by B & Sorted by IV \\
\hline Low & 0.23 & -0.01 \\
\hline 2 & 1.15 & 0.94 \\
\hline 3 & 0.76 & 0.71 \\
\hline 4 & 0.70 & 0.63 \\
\hline High & 0.51 & 0.51 \\
\hline All & 3.35 & 2.78 \\
\hline \multicolumn{3}{|c|}{$\begin{array}{l}\text { Note. All values are monthly average returns in (\%). For the considered } \\
\text { S\&P } 500 \text { stocks of the Industrials and Materials sector, the B and IV } \\
\text { values were computed and sorted according to their quintiles. }\end{array}$} \\
\hline
\end{tabular}




\section{Analysis and Discussion of $\mathrm{H4}$}

For the analysis of $H 4$, I computed for the B and the IV a range from the highest and the lowest values and I determined the five quintile values. According to the quintiles, I assigned the return data in the best case to the portfolio sizes 10, 15 and max amount of stocks. Since I combined the 1 and 2 quintiles and 4 and 5 quintile for low and high values in the analysis, a three dimensional selection was possible of low, medium, and high scale values. The stock data of the summer IV values contained three outliers for the highest IV values, which I corrected, and I started to compute the IV quintiles from the IV value of $\left(I V_{\text {Highest_quintile }}=0.03318\right)$ until the lowest IV value.
From Table 4, I can find that a winter and summer effect was present in the investigated data. High B values seemed to outperform during the winter months with $\left(r_{B_{-} H i g h}=4.77-4.85 \%\right.$ per month $)$, compared to the other investigated stock selections, although the Medium sized B values exhibited similar high monthly returns. A continuous difference, that smaller stock portfolios of 10 stocks are more profitable than a large number of stocks in a portfolio, could not be found. The IV returns outperformed in a medium quintile selection in the winter months with $\left(r_{I \_\_ \text {Medium }}=\right.$ 4.03-4.07 \% per month), compared to the other investigated stock selections. I could not reject the Null Hypothesis 4 at a $1 \%$ alpha level because the high ${ }_{B}$ and high $_{\text {IV }}$ return selections in the winter months were not greater than the remaining return values.

Table-4: Portfolios of Industrials and Materials sector stocks, 1999-2018

\begin{tabular}{|c|c|c|c|c|c|c|c|}
\hline Seasonality & & & Portfolios (Stocks) & & & & \\
\hline \begin{tabular}{l|l} 
Portfolios (Stocks) & Low
\end{tabular} & B & IV & & B & IV & B & IV \\
\hline 10 & 1.67 & 1.68 & 10 & 0.35 & 0.53 & 1.01 & 1.11 \\
\hline 15 & 2.09 & 2.54 & 15 & 0.86 & 0.95 & 1.48 & 1.75 \\
\hline $\operatorname{Max}(53)$ & 3.23 & 3.71 & $\operatorname{Max}(54 \mid 67)$ & 0.42 & 0.36 & 1.83 & 2.04 \\
\hline \begin{tabular}{l|l|} 
Portfolios (Stocks) & Medium \\
\end{tabular} & $\mathrm{B}$ & IV & & $\mathrm{B}$ & IV & $\mathrm{B}$ & IV \\
\hline 10 & 4.83 & 4.06 & 10 & -0.07 & -0.27 & 2.38 & 1.90 \\
\hline 15 & 4.22 & 4.03 & 15 & 0.54 & -0.4 & 2.38 & NA \\
\hline $\operatorname{Max}(23 \mid 31)$ & 4.18 & 4.07 & $\operatorname{Max}(18 \mid 175)$ & 0.61 & -0.37 & 2.40 & 1.85 \\
\hline Portfolios (Stocks) $\mid$ High & $\mathrm{B}$ & IV & & $\mathrm{B}$ & IV & $\mathrm{B}$ & IV \\
\hline 10 & 4.77 & 2.84 & 10 & -0.9 & -0.11 & 1.94 & 1.19 \\
\hline 15 & 4.85 & NA & 15 & -0.98 & NA & 1.94 & NA \\
\hline $\operatorname{Max}(16 \mid 10)$ & 4.82 & 2.84 & $\operatorname{Max}(21 \mid 10)$ & -1.29 & -0.11 & 1.77 & 1.37 \\
\hline
\end{tabular}

Note. Low, medium, and high represents the quintiles that were combined. This means that five dimensional quintiles were computed for a B and an IV range and reduced to three dimensions. For the lower and higher quintiles that were combined and reduction to three dimensions were (i.e., $5+4$ quintile $=$ high and $1+2$ quintile $=$ low). Three portfolio sizes were considered 10 stocks, 15 stocks, and all of the remaining stocks in the Max stock portfolio for a comparison. In the parentheses the amount of the selected stocks were reported (B|IV). NA means not assigned or no values existed. The stocks were selected from the S\&P500 Industrials and Materials sectors data. In the table, a differentiation is displayed for the monthly returns (\%) of the portfolios in winter and summer months, for three dimensions, and for B and IV selection results.

\section{Analysis and Discussion of $\mathrm{H5}$}

For the analysis of $\mathrm{H5}$, I used the computed ranges of the $\mathrm{B}$ and the IV values and the determination of the five quintile values from $\mathrm{H} 4$. According to the quintiles, I assigned the return data in the best case to the portfolio sizes 10,15 and max amount of stocks, however, stock deviations occurred for the portfolios. Since I combined the 1 and 2 quintiles for low values and 4 and 5 quintile for high values in the analysis, I could again obtain three selection dimensions that represented low, medium, and high values. I controlled for seasonality and computed the arithmetic monthly mean return.

If the stocks were held over both periods, winter and summer months, then a low B\&IV $_{\text {combination }}$ strategy, with a 10 stock portfolio, should be selected on average according to Table 5. Similar to the results of $\mathrm{H} 4$, a continuous difference could not be found between the maximum number of stock portfolios and the small number of stock portfolios with 10 stocks. If high returns are the objective, then a high B\&IV $_{1}$ combination strategy should be selected during the winter months with $\left(r_{H i g h \text { B\&IV }}=5.36 \%\right.$ per month). I could not reject the Null Hypothesis 5 at a $1 \%$ alpha level, since the high $\mathrm{B}_{\mathrm{B} I V}$ combination during the winter months was significantly more profitable compared to the other medium ${ }_{\text {B\&IV }}$ or low B\&IV combinations, but, only for a 5 stock portfolio and not for a 10 stock portfolio. 
Table-5: Portfolios of Industrials and Materials sector stocks, 1999-2018

\begin{tabular}{|c|c|c|c|c|c|}
\hline Seasonality & & Winter & Stocks & Summer & Mean \\
\hline \multicolumn{6}{|c|}{\begin{tabular}{l|l} 
Stocks & Low $_{\text {B\&IV }}$ \\
\end{tabular}} \\
\hline 10 & & 3.68 & 10 & 0.58 & 2.13 \\
\hline 15 & & 3.57 & 15 & 0.48 & 2.03 \\
\hline $\operatorname{Max}(34)$ & & 3.26 & Max (49) & 0.35 & 1.81 \\
\hline \multicolumn{2}{|c|}{\begin{tabular}{l|l} 
Stocks & Medium \\
B\&IV
\end{tabular}} & & & Stocks & \\
\hline \multicolumn{2}{|l|}{10} & 3.66 & 5 & -0.07 & 1.80 \\
\hline \multicolumn{2}{|l|}{11} & 3.73 & 15 & NA & NA \\
\hline \multicolumn{2}{|l|}{$\operatorname{Max}(11)$} & 3.73 & $\operatorname{Max}(5)$ & -0.07 & 1.83 \\
\hline \multicolumn{2}{|c|}{\begin{tabular}{l|l} 
Stocks & High $_{\text {B\&IV }}$ \\
\end{tabular}} & & & Stocks & \\
\hline \multicolumn{2}{|c|}{ r } & 5.36 & 7 & -1.78 & 1.79 \\
\hline \multicolumn{2}{|l|}{15} & NA & 15 & NA & NA \\
\hline \multicolumn{2}{|l|}{ Max (5) } & 5.36 & $\operatorname{Max}(7)$ & -1.78 & 1.79 \\
\hline \multicolumn{6}{|c|}{$\begin{array}{l}\text { Note. Low, medium, and high represents the quintiles that were combined. This means } \\
\text { that five dimensional quintiles were computed for a B and an IV range and reduced to } \\
\text { three dimensions. For the lower and higher quintiles that were combined and reduction } \\
\text { to three dimensions were (i.e., } 5+4 \text { quintile = high and } 1+2 \text { quintile }=\text { low). Three } \\
\text { portfolio sizes were analyzed, } 10 \text { stock, } 15 \text { stock and all of the remaining stocks were } \\
\text { reported in the Max portfolio for the selected quintiles, however stock deviations } \\
\text { occurred. In the parentheses the amount of the selected stocks were reported. NA } \\
\text { means not assigned or no values existed. The stocks were selected from the S\&P500 } \\
\text { Industrials and Materials sectors data. In the table, a differentiation is displayed for the } \\
\text { monthly returns }(\%) \text { of the portfolios in winter and summer months, for three } \\
\text { dimensions, and for B\&IV combination selection results. }\end{array}$} \\
\hline
\end{tabular}

\section{Analysis and Discussion of H6}

For the analysis of H6, I developed two tables for a comparison, in which I computed the average return per month for 15 individual strategies, differed by seasonality, exhibiting the annual returns, displaying the standard deviation, and the Sharpe Ratio. I considered in the table the security data from the S\&P 500 Industrials and Materials sector stocks for the risk strategies, the S\&P 500 data for the returns of all stocks, and the T-Bills returns from the Kenneth French data (as reported in Table 1), and I annualized the returns of the 15 different security switch strategy combinations. For the standard deviation of the strategy portfolios, I computed the average standard deviation from the stocks that were considered for each strategy. This method of computation led to a higher portfolio standard deviation as normally assumed because correlation effects, as mentioned by Markowitz [15], were not considered through this computation method. However, the deviations that occur for the annualized returns and the deviation that occurs for the portfolio standard deviations were not critical for a comparison of the profitability of the switch combined strategies.
From Table A3 in the Appendix and Table 6, I can find that Strategy 1 has the highest returns of $\left(r_{\text {Strategy } 1}=108.40 \%\right.$ p.a. $)$. For Strategy 1 , a medium B\&IV approach was considered for the winter months with a Max stock portfolio, and for the strategy switch, a low IV approach was considered for the summer months with a 10 stock portfolio. However, Strategy 2 had the best risk and reward relation, due to a low standard deviation, which had an effect on the Sharpe Ration $(\mathrm{SR})$, where $\left(\mathrm{SR}_{\text {Strategy } 2}=4.66\right)$. The most by private investors commonly used Strategy 15, of investing in all stocks during the winter months and switching during the summer months in T-Bills, had the lowest volatility $(\mathrm{Vol})$ and had the lowest returns compared to the other investigated switch strategies with $\left(r_{\text {Strategy } 15}=\right.$ $9.77 \%$ p.a.) and ( Vol $_{\text {Strategy } 15}=9.63 \%$ p.a. $)$. I cannot reject the Null Hypothesis 6 at a $1 \%$ alpha level, since the high $\mathrm{B}_{\mathrm{B}}$ during the winter months and the low $\mathrm{B}_{\mathrm{B} \text { IV }}$ during the summer months switch strategy was not significantly more profitable compared to the other risk stock switch strategies (see Strategy 1 in Table 6). 
Table-6: Seasonality Switch Strategy for S\&P 500 index, Industrials and Materials sectors and T-Bills, from 1999 2018

\begin{tabular}{|c|c|c|c|c|c|}
\hline & & & Performance & & \\
\hline$\#$ & Winter & Summer & return p.a. $(\%)$ & STD p.a. $(\%)$ & Sharpe \\
\hline 1 & Medium_B\&IV_Max stocks $_{\text {B }}$ & Low $_{\text {IV_115 stocks }}$ & 108.40 & 26.34 & 4.12 \\
\hline 2 & Medium $_{\text {B\&IV_Max stocks }}$ & LoW $_{\text {B_15 stocks }}$ & 106.29 & 22.81 & 4.66 \\
\hline 3 & High $_{\text {B_15 stocks }}$ & Low IV_ 15 stocks & 96.71 & 30.56 & 3.16 \\
\hline 4 & High $_{\text {B_15 stocks }}$ & LoW $_{\text {B_15 stocks }}$ & 94.71 & 27.03 & 3.50 \\
\hline 5 & Medium $_{\text {B\&IV_Max stocks }}$ & T-Bills & 90.34 & 17.64 & 5.12 \\
\hline 6 & High $_{\text {B_15 stocks }}$ & LoW $_{\text {B\&IV } 10 \text { stocks }}$ & 88.61 & 28.79 & 3.08 \\
\hline 7 & Medium_IV_Max stocks $_{\text {I }}$ & Low $_{\text {IV_15 stocks }}$ & 80.00 & 27.47 & 2.91 \\
\hline 8 & High $_{\text {B_15 stocks }}$ & T-Bills & 79.59 & 21.78 & 3.65 \\
\hline 9 & Medium IV_Max stocks $_{\text {I }}$ & Low $_{\text {B_15 stocks }}$ & 78.15 & 27.47 & 2.85 \\
\hline 10 & Medium IV_Max stocks $_{\text {I }}$ & Low $_{\text {B\&IV_10 stocks }}$ & 72.53 & 25.70 & 2.82 \\
\hline 11 & Medium $_{\text {B\&IV_10 stocks }}$ & Low $_{\text {B\&IV_10 stocks }}$ & 65.92 & 24.66 & 2.67 \\
\hline 12 & Medium IV_Max stocks $_{\text {IV }}$ & T-Bills & 64.22 & 18.68 & 3.44 \\
\hline 13 & Materials & T-Bills & 59.37 & 16.61 & 3.57 \\
\hline 14 & Industrials & T-Bills & 54.29 & 17.30 & 3.14 \\
\hline 15 & All Stocks & T-Bills & 9.77 & 9.63 & 1.01 \\
\hline
\end{tabular}

Note. The stocks were selected from the S\&P500 data and the S\&P500 Industrials and Materials sector data. The TBills were selected from Kenneth French data. The returns are annualized returns in (\%). The Sharpe Ratio was computed without the risk free adjustment. The standard deviation is an average and does not consider correlations effects. In the table, a strategy switch for winter and summer months is displayed.

\section{CONCLUSION}

In conclusion, this study's findings can corroborate Fiore and Saha's [12] reported results for risk stock strategies. I found out that during the winter months a high $_{\mathrm{B}}$ and a medium $\mathrm{B \& IV}$ until high $\mathrm{B} \& \mathrm{IV}$ stock selection was most profitable to trade, and for the summer months a low IV, B, IV\&B stock selection was most profitable to invest, in regard of risk stock strategies with a seasonality switch. The findings of the study differed to Fiore and Saha's [12] study for the results of the strategy switch between a common all stock and T-Bills strategy switch, where Fiore and Saha reported in their study, during the time period of 19682012, a circa $48.20 \%$ larger average annual return (and volatility) compared to the findings in this study during 1999-2018. This could mean that the investigated time period of Fiore and Saha was more profitable compared to this study's time period. Interestingly, the profitability of the strategy switches are in this study significantly larger compared to the findings in Fiore and Saha's [12] study, with for example for the highest annual return of $\left[r_{\text {Strategy }]}=108.40 \%\right.$ from Table 6 in this study versus highest returns of $r_{\text {Strategy } 2 \text { leveraged }}=$ $23.77 \%$ in Fiore and Saha's study in Table 6]. I can speculate that a portfolio selection of the individual stocks of the two most profitable stock index sectors (Industrials and Materials) brought a large and more profitable difference for the study's results.

At this point the research question can be answered: How does seasonality impact the profitability of risk stock strategies while controlling for stock market sectors for U.S. security portfolios? I can find that seasonally are present in the S\&P 500 stock market and one can capitalized on the seasonality effect by switching the strategy according to the strategy comparison made in Table 6. Other than reported by Bouman and Jacobsen [6], I could find significant findings for seasonality's between the investigated stock market sectors reported in Table 2. An 80 year long time period was not necessary as reported by Jacobsen and Visaltanachoti [11] to obtain significant results, as mentioned, because of a stock selection according to sectors and a portfolio construction.

This study's findings can contribute to positive social change because a risk stock strategy switch considering seasonality's for portfolio selection was investigated. Private investors can now adjust their strategy, of simply buying all stocks in the winter months and switching to T-Bills in the summer months, to a more profitable strategy, of considering medium and high risk values in the winter months and considering low risk values in the summer months while selecting the stocks from the two most robust stock index sectors and while constructing portfolios according to Table 6 . For other researchers, it can be a task to investigate if the recommended stock sectors Industrials and Materials are also robust, as found in this study, in future stock markets and in future occurring crises. Also the finding, that a stock selection from stock market sectors and the construction of portfolio can bring a significant difference to the result of seasonality switch risk stock strategies, can be further analyzed by other researchers to corroborate or reject this study's findings.

\section{REFERENCES}

1. Asness, C. S., Frazzini, A., \& Pedersen, L. H. (2012). Leverage aversion and risk parity. 
Financial Analysts Journal, 68(1), 47-59. doi:10.2469/faj.v68.n1.1

2. Baker, M., Bradley, B., \&Wurgler, J. (2011). Benchmarks as limits to arbitrage: Understanding thelow-volatility anomaly. Financial Analysts Journal, 67(1), 40-54. doi:10.2469/faj.v67.n1.4

3. Chow, T. M., Hsu, J. C., Kuo, L. L., \& Li, F. (2014). A study of low volatility portfolio construction methods. Journal of Portfolio Management, 40(4), 89-105. doi:10.3905/jpm.2014.40.4.089

4. Fong, W. M., \& Koh, T.(2015). Strategic asset allocation with low-risk stocks: A bootstrap analysis. Journal of Investment Management, 13(2), 39-58. Retrieved from https://www.joim.com/wpcontent/uploads/emember/downloads/10.pdf

5. Walkshäusl, C. (2013). The high returns to low volatility stocks are actually a premium on high quality forms. Review of Financial Economics, 22(4), 180-186.

6. Bouman S., \& Jacobsen, B. (2002). The Halloween indicator, sell in May and go away: Another puzzle. American Economic Review, 92(5), 16181635 .

7. Hong, H., \& Yu, J. (2009). Gone fishin': Seasonality in trading activity and asset prices. Journal of Financial Markets, 12(4), 672-702.

8. Kamstra, M. J., Kramer, L. A., \& Levi, M. D. (2003). Winter blues: A SAD stock market cycle. American Economic Review, 93(1), 324-343.

9. Cao, M., \& Wei, J. (2005) Stock market returns: A note on temperature anomaly. Journal of Banking and Finance, 29(6), 1559-1573.

10. Jacobsen, B., \& Marquering, W. A. (2008). Is it the weather? Journal of Banking and Finance, 32(4), 526-540.

11. Jacobsen, B., \&Visaltanachoti, N. (2009). The Halloween effect in U.S. sectors. The Financial Review, 44(3), 437-459.

12. Fiore, C. \& Saha, A. (2015). A tale of two anomalies: Higher returns of low-risk stocks and return seasonality. The Financial Review, 50, 257273.

13. Sharpe,W. F. (1964). Capital asset prices: A theory of market equilibrium under conditions of risk. Journal of Finance, 19(3), 425-442.

14. Lintner, J. (1965). The valuation of risk assets and the selection of risky investments in stock portfolios and capital budgets. Review of Economics and Statistics, 47, 13-37. Retrieved from https://www.jstor.org/stable/1924119
15. Markowitz, H. (1952). Portfolio selection. The Journal of Finance, 7(1), 77-91. doi:10.1111/j.1540-6261.1952.tb01525.x

16. Ang, A., Hodrick, R. J., Xing, Y., \& Zhang, X. (2006). The cross-section of volatility and expected stock returns. Journal of Finance, 61(1), 259-299.

17. Ang, A., Hodrick, R. J. Xing, Y., \& Zhang, X. (2009). High idiosyncratic volatility of low returns: International and further U.S. evidence. Journal of Financial Economics, 91(1), 1-23.

18. Malkiel, B. G., \& Xu, Y. (2002). Idiosyncratic risk and security returns. Working Paper, University of Texas at Dallas. Retrieved from https://personal.utdallas.edu/ yexiaoxu/IVOT_f.PD $\mathrm{F}$

19. Ewens, M., Jones, C., \& Rhodes-Kropf, M. (2013). The price of diversifiable risk in venture capital andprivate equity. Review of Financial Studies, 26(8), 1853-1889.

20. Black, F. (1972). Capital market equilibrium with restricted borrowing. Journal of Business ,45(3), 444-455.https://www.jstor.org/stable/2351499

21. Black, F., Jensen, M. C., \& Scholes, M. (1975). The capital asset pricing model: Some empirical tests. Studies in the Theory of Capital Markets. Retrieved from https://ssrn.com/abstract=908569

22. Haugen, R. A.,\& Heins, A. J. (1975). Risk and the rate of return on financial assets: Some old wine in newbottles. Journal of Financial and Quantitative Analysis, 10, 775-784. doi:10.2307/2330270

23. Fama, E. F., \& French, K. R. (1992). The crosssection of expected stock returns. Journal of Finance, 47,427-465.

24. Bird, R., Gao, X., \& Yeung, D. (2016). Time-series and cross-sectional momentum strategies under alternative implementation strategies. Australian Journal of Management, 42(2), 230-251.

25. Ren, L., \& Ren, P. (2018). Applying a combined max-min simple moving average trading strategy to market indexes. Economics, Management, \& Financial Markets, 13(2), 11-23. Retrieved from https://www.ceeol.com/search/articledetail id $=676861$

26. Berk, J., \& DeMarzo, P. (2011). Corporate finance. Boston, MA: Pearson Education.

27. Abbey, B. S., \& Doukas, J. A. (2012). Is technical analysis profitable for individual currency traders? Journal of Portfolio Management, 39(1), 142-150. doi:10.3905/jpm.2012.39.1.142

\section{Appendix}

Test of robustness for seasonality's. 
Table-A1: S\&P 500 sectors from 1999-2008

\begin{tabular}{|l|c|c|c|}
\hline \multicolumn{4}{|c|}{ Average monthly return (\%) } \\
\hline & Winter & Summer & Mean \\
\hline Communication Service & 0.30 & -0.14 & 0.08 \\
\hline Consumer Discretionary & 1.69 & -0.40 & 0.65 \\
\hline Consumer Staples & 0.67 & 0.42 & 0.54 \\
\hline Energy & 0.25 & -0.14 & 0.05 \\
\hline Financials & 0.52 & -0.19 & 0.17 \\
\hline Health Care & 1.01 & 0.38 & 0.70 \\
\hline Industrials & $\mathbf{2 . 8 2}$ & $\mathbf{- 0 . 3 7}$ & $\mathbf{1 . 2 3}$ \\
\hline Information Technology & 0.60 & -0.16 & 0.22 \\
\hline Materials & $\mathbf{3 . 3 9}$ & $\mathbf{- 0 . 4 6}$ & $\mathbf{1 . 4 7}$ \\
& & & $\mathbf{1 . 0 9}$ \\
\hline Real Estate & $\mathbf{2 . 0 3}$ & $\mathbf{0 . 1 5}$ & 0.68 \\
\hline Utilities & 1.36 & 0.00 & \\
\hline
\end{tabular}

Note. All values are monthly average returns in (\%). The results were computed for each of the 11 sectors of the S\&P 500 stocks. In the table, a differentiation occurred between winter and summer results of the sector return data. The arithmetic mean displays the average monthly return for each sector in combination of both time periods.

Table-A2: S\&P 500 sectors from 2009-2018

\begin{tabular}{|l|c|c|c|}
\hline & \multicolumn{3}{|c|}{ Average monthly return (\%) } \\
\hline & Winter & Summer & Mean \\
\hline Communication Service & 2.97 & 1.36 & 2.17 \\
\hline Consumer Discretionary & $\mathbf{4 . 9 3}$ & $\mathbf{0 . 9 0}$ & $\mathbf{2 . 9 1}$ \\
\hline Consumer Staples & 1.77 & 1.27 & 1.52 \\
\hline Energy & 2.49 & -0.04 & 1.23 \\
\hline Financials & 2.49 & 0.77 & 1.63 \\
\hline Health Care & $\mathbf{5 . 0 5}$ & $\mathbf{1 . 5 6}$ & $\mathbf{3 . 3 0}$ \\
\hline Industrials & 4.37 & 0.86 & 2.61 \\
\hline Information Technology & $\mathbf{5 . 1 7}$ & $\mathbf{1 . 8 0}$ & $\mathbf{3 . 4 9}$ \\
\hline Materials & 4.26 & 0.36 & 2.31 \\
\hline Real Estate & 3.48 & 1.01 & 2.25 \\
\hline Utilities & 1.77 & 1.46 & 1.62 \\
\hline Note. All val & & & \\
\hline
\end{tabular}

Note. All values are monthly average returns in (\%). The results were computed for each of the 11 sectors of the S\&P 500 stocks. In the table, a differentiation occurred between winter and summer results of the sector return data. The arithmetic mean displays the average monthly return for each sector in combination of both time periods.

Table-A3: Seasonality Switch Strategy for S\&P 500 index, Industrials and Materials sectors and T-Bills, from

\begin{tabular}{|c|c|c|c|c|c|}
\hline \multicolumn{6}{|c|}{ 1999-2018 } \\
\hline \# & Winter & return p.m. (\%) & Summer & return p.m. (\%) & return p.a. $(\%)$ \\
\hline 1 & Medium $_{\text {B\&IV Max stocks }}$ & 5.36 & LoW $_{\text {IV } 15 \text { stocks }}$ & 0.95 & 108.40 \\
\hline 2 & Medium $_{\text {B\&IV_Max stocks }}$ & 5.36 & Low $_{\text {B_1 } 15 \text { stocks }}$ & 0.86 & 106.29 \\
\hline 3 & High $_{\text {B_15 stocks }}$ & 4.85 & Low $_{\text {IV _ } 15 \text { stocks }}$ & 0.95 & 96.71 \\
\hline 4 & High $_{\text {B_15 stocks }}$ & 4.85 & Low $_{\text {B_15 stocks }}$ & 0.86 & 94.71 \\
\hline 5 & Medium $_{\text {B\&IV_Max stocks }}$ & 5.36 & T-Bills & 0.15 & 90.34 \\
\hline 6 & High $_{\mathrm{B}} 15$ stocks & 4.85 & Low $_{\text {B\&IV } 10 \text { stocks }}$ & 0.58 & 88.61 \\
\hline 7 & Medium $_{\text {IV_Max stocks }}$ & 4.07 & Low $_{\text {IV_15 stocks }}$ & 0.95 & 80.00 \\
\hline 8 & High $_{\text {B_15 stocks }}$ & 4.85 & T-Bills & 0.15 & 79.59 \\
\hline 9 & Medium $_{\text {IV_Max stocks }}$ & 4.07 & Low $_{\text {B_ } 15 \text { stocks }}$ & 0.86 & 78.15 \\
\hline 10 & Medium $_{\text {IV_Max stocks }}$ & 4.07 & LoW $_{\text {B\&IV } 10 \text { stocks }}$ & 0.58 & 72.53 \\
\hline 11 & Medium $_{\text {B\&IV_10 stocks }}$ & 3.73 & Low $_{\text {B\&IV_10 stocks }}$ & 0.58 & 65.92 \\
\hline 12 & Medium $_{\text {IV _Max stocks }}$ & 4.07 & T-Bills & 0.15 & 64.22 \\
\hline 13 & Materials & 3.81 & T-Bills & 0.15 & 59.37 \\
\hline 14 & Industrials & 3.53 & T-Bills & 0.15 & 54.29 \\
\hline 15 & All Stocks & 0.63 & T-Bills & 0.15 & 9.77 \\
\hline
\end{tabular}

Note. In the table, monthly average returns and annualized returns are reported. A strategy switch for winter and summer months is displayed. The stocks (other than All, Materials, Industrials, or T-Bills) were selected from the S\&P500 Industrials and Materials sector data. 